\title{
Nivolumab-induced hypophysitis in a patient with advanced malignant melanoma
}

\author{
Yudai Okano ${ }^{1)}$, Tetsurou Satoh ${ }^{1)}$, Kazuhiko Horiguchi ${ }^{1)}$, Minoru Toyoda ${ }^{2)}$, Aya Osaki ${ }^{1)}$, \\ Shunichi Matsumoto ${ }^{1)}$, Takuya Tomaru' ${ }^{1)}$, Yasuyo Nakajima ${ }^{1)}$, Sumiyasu Ishii ${ }^{1)}$, Atsushi Ozawa ${ }^{1)}$, \\ Nobuyuki Shibusawa $^{1)}$, Takehiro Shimada ${ }^{3)}$, Tetsuya Higuchi ${ }^{3)}$, Kazuaki Chikamatsu ${ }^{2)}$ and \\ Masanobu Yamada ${ }^{1)}$ \\ 1) Department of Medicine and Molecular Science, Gunma University Graduate School of Medicine, Maebashi 371-8511, Japan \\ 2) Department of Otolaryngology-Head and Neck Surgery, Gunma University Graduate School of Medicine, Maebashi \\ 371-8511, Japan \\ 3) Department of Diagnostic, Interventional Radiology and Nuclear Medicine, Gunma University Graduate School of Medicine, \\ Maebashi 371-8511, Japan
}

\begin{abstract}
The anti-programmed cell death-1 monoclonal antibody (mab), nivolumab has recently been approved for the treatment of unresectable or metastatic malignant melanoma and non-small-cell lung cancers in Japan. Ipilimumab, an anti-cytotoxic T lymphocyte antigen-4 mab for malignant melanoma that was approved earlier than nivolumab in Western countries, is known to frequently cause endocrine immune-related adverse events such as hypophysitis and thyroid dysfunction. We herein report a patient with advanced melanoma who appeared to develop hypophysitis as a consequence of the inhibition of PD-1 by nivolumab. One week after the $6^{\text {th }}$ administration of nivolumab, the patient developed progressive fatigue and appetite loss. Laboratory data on admission for the $7^{\text {th }}$ administration of nivolumab showed eosinophilia and hyponatremia. Since ACTH and cortisol levels were low, nivolumab was discontinued and a large dose of hydrocortisone $(100 \mathrm{mg} / \mathrm{d})$ was promptly administered intravenously. A magnetic resonance imaging scan revealed the mild enlargement of the anterior pituitary gland and thickening of the stalk with homogenous contrast. A detailed assessment of anterior pituitary functions with hypothalamic hormone challenges showed that hormonal secretions other than ACTH and TSH were normal. With a replacement dose of hydrocortisone $(20 \mathrm{mg} / \mathrm{d})$, the $7^{\text {th }}$ administration of nivolumab was completed without exacerbating the patient's general condition. The present report provides the first detailed endocrinological presentation of nivolumab-induced hypophysitis showing the enlargement of the pituitary gland and stalk in a malignant melanoma patient in Japan. Oncologists and endocrinologists need to be familiar with potentially life-threatening hypophysitis induced by immune-checkpoint inhibitors.
\end{abstract}

Key words: Malignant melanoma, Nivolumab, Hypophysitis, Secondary adrenal insufficiency, Treatment

IDIOPATHIC AUTOIMMUNE HYPOPHYSITIS (AH), often referred to as lymphocytic hypophysitis, is a rare immune-mediated inflammatory disorder that causes pituitary dysfunction. Idiopathic $\mathrm{AH}$ frequently occurs during the last month of pregnancy or during the first 2 months postpartum [1]. Hypophysitis also occurs as one of the organ manifestations of IgG4related disease that preferentially affects middle-aged

Submitted Mar. 28, 2016; Accepted Jun. 23, 2016 as EJ16-0161 Released online in J-STAGE as advance publication Jul. 20, 2016 Correspondence to: Tetsurou Satoh, M.D., Ph.D., Department of Medicine and Molecular Science, Gunma University Graduate School of Medicine, Maebashi 371-8511, Japan.

E-mail address: tsato@gunma-u.ac.jp

(c) The Japan Endocrine Society to elderly men $[2,3]$. In $\mathrm{AH}$, activated lymphocytes infiltrate the pituitary gland/pituitary stalk, resulting in the enlargement/thickening of lesions, respectively, and disturb the secretion of anterior and/or posterior pituitary hormones to varying degrees $[1,4]$. The secretion of anterior pituitary hormones in $\mathrm{AH}$ appears to be disturbed in a characteristic order: the secretion of ACTH is the most frequently and initially disturbed, followed by TSH, gonadotropins, prolactin, and GH [1].

Recently developed cancer immunotherapies against immune-checkpoints such as cytotoxic T-lymphocyte antigen-4 (CTLA-4) and programmed cell death-1 (PD-1), two co-inhibitory receptors expressed on $\mathrm{T}$ cells that inhibit $\mathrm{T}$ cell activation, are promising 
treatments for advanced malignancies because they enhance innate immune responses [5,6]. Ipilimumab, an anti-CTLA-4 IgG1 monoclonal antibody (mab), was approved for the treatment of advanced malignant melanoma in 2011 and 2015 in the United States and Japan, respectively. Certain metastatic cancers avoid detection by the host immune system by expressing molecules (PD-L1 and PD-L2 ligands) that enhance the blockade of $\mathrm{T}$ cell activation through the $\mathrm{PD}-1$ receptor expressed on T cells $[5,6]$. The blockade of the PD-1 receptor is an alternative promising treatment because it activates $T$ cells to eliminate cancer cells [5-7], and the anti-PD-1 IgG4 mab, nivolumab has recently been approved for advanced malignant melanoma and nonsmall-cell lung cancers in Japan.

In addition to these evidence-based immune-mediated anti-cancerous effects, ipilimumab frequently induces several endocrine immune-related adverse events (irAEs) such as hypophysitis and destructive thyroiditis as a consequence of enhanced $\mathrm{T}$ cell functions [8-12]. Although hypophysitis induced by nivolumab has also been reported, its incidence in Western countries appears to be lower than that observed with ipilimumab [12]. A phase II trial using nivolumab with the recruitment of 35 malignant melanoma patients in Japan showed that nivolumab-induced hypophysitis developed in one patient (2.9\%) [13]. However, the incidence and clinical characteristics of hypophysitis induced by these immune-checkpoint inhibitors have not yet been examined in large Japanese cohorts.

We herein report a patient with advanced malignant melanoma associated with hypophysitis that appeared to be induced by the inhibition of PD-1 with nivolumab.

\section{Patient}

A 50-year-old man with essential hypertension presented to the Department of Otolaryngology-Head and Neck Surgery in Gunma University Hospital with a tumor in the oropharynx in August 2015. He had no specific previous or family medical histories. He drank alcohol (360 mL Japanese sake/d) and smoked 30 cigarettes/d for 25 years. An endoscopic examination identified a torose tumor that was black and white in color on the right side of the lingual root (Fig. 1A). A pathological examination of biopsy specimens resulted in a diagnosis of malignant melanoma. The uptake of $18 \mathrm{~F}$-fluorodeoxyglucose (FDG) by the primary tumor (standard uptake value (SUV) max; 8.3) and the left cervical (SUVmax; 7.0) and upper mediastinal lymph nodes (SUVmax; 3.1) was detected on a positron emission tomography/computed tomography (PET/CT) scan (Fig. 1B). The weak uptake of 18FFDG to the bilateral hilar lymph nodes was considered to be non-specific. Since radical surgery or radiation was difficult to perform due to multiple lymph node metastasis, chemotherapy with dacarbazine $(120 \mathrm{mg} /$ $\left.\mathrm{m}^{2}, \mathrm{~d} 1-\mathrm{d} 5\right)$ was prescribed. However, tumor progression was observed after chemotherapy on a subsequent

A

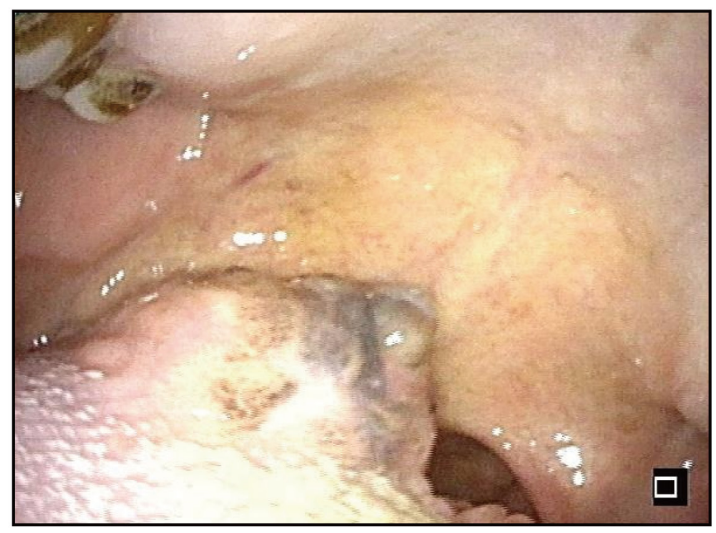

B

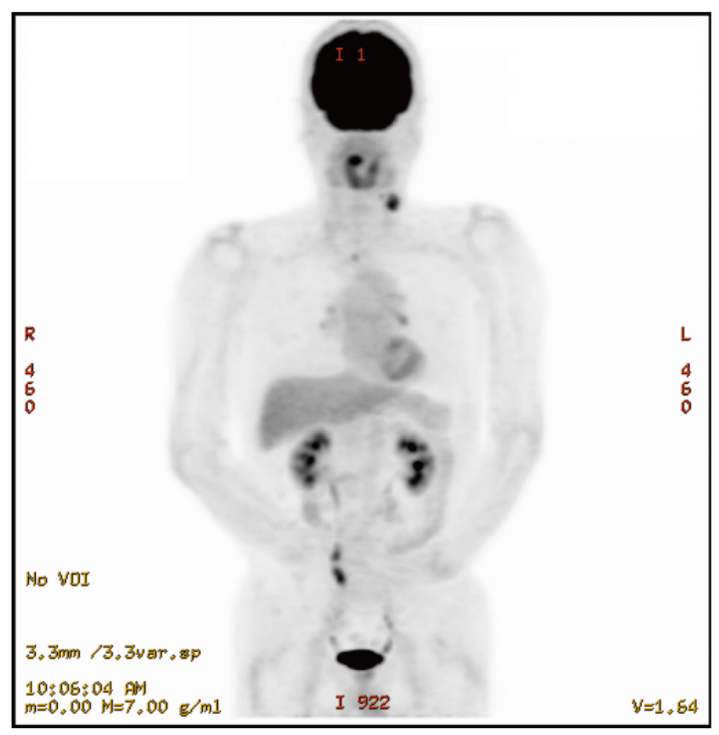

Fig. 1 A. Endoscopic findings of malignant melanoma on the right side of the lingual root. B. Findings on an 18F-fluorodeoxyglucose (FDG)/positron emission tomography scan performed in August 2015. The significant uptake of $18 \mathrm{~F}-\mathrm{FDG}$ by the primary tumor and left cervical and upper mediastinal lymph nodes was observed. 
PET/CT scan (data not shown); therefore, the administration of nivolumab $(2 \mathrm{mg} / \mathrm{kg})$ was started every 3 weeks from September 2015. Nivolumab was found to be effective for the primary and mediastinal lesions on a follow-up PET/CT scan performed in January 2016, but had weaker effects on metastatic cervical lymph nodes (data not shown).

One week after the $6^{\text {th }}$ administration of nivolumab, the patient developed progressive fatigue and appetite loss. On admission for the $7^{\text {th }}$ administration of nivolumab, the patient was unable to walk because of general weakness. Laboratory findings on admission showed no anemia or liver dysfunction, but revealed eosinophilia and hyponatremia. The patient did not have headaches, but exhibited thirst, and dehydration was apparent from elevated blood urea nitrogen and creatinine levels; however, blood glucose levels were normal (Table 1). Since nivolumab is known to cause endocrine irAEs such as hypophysitis, albeit rarely $[8,10-12]$, a hormonal examination was performed (Table 2). ACTH and cortisol levels as well as dehydroepiandrosterone sulfate levels were low. Insulinlike growth factor-1 (IGF-1) levels were also low and this may have been due to malnutrition. In contrast, prolactin levels were slightly elevated. Thyroid function tests revealed normal FT3, FT4, and TSH levels. Basal LH and FSH levels as well as testosterone levels were normal. Plasma osmolarity was decreased due to hyponatremia, whereas urine osmolarity was normal. Based on these laboratory findings, we suspected nivolumab-induced hypophysitis associated with an isolated ACTH deficiency in this case.

A large dose of hydrocortisone $(100 \mathrm{mg} / \mathrm{d})$ was promptly administered intravenously. His general condition as well as eosinophilia and hyponatremia improved during the next few days, and the i.v. administration of hydrocortisone was changed to the oral route $(30 \mathrm{mg} / \mathrm{d})$ on $\mathrm{d} 3$, and was subsequently reduced to $20 \mathrm{mg} / \mathrm{d}$ on $\mathrm{d} 10$. Compared with the findings on a magnetic resonance imaging (MRI) scan performed on July 2015 (Fig. 2A), mild enlargement of the pituitary gland and thickening of the stalk with homogenous enhancement were observed on a MRI scan performed on $\mathrm{d} 5$ (Fig. 2B). The high intensity in the posterior pituitary gland on a T1-weighted image was preserved (data not shown). These MRI findings were compatible with those reported previously in AH [1], and excluded pituitary metastasis of malignant melanoma or pituitary adenoma. Since immune checkpoint inhib-
Table 1 Hematological and biochemical findings on admission

\begin{tabular}{lc}
\hline Cell blood count & \\
$\mathrm{Hct}$ & $42.7 \%(40.0-52.0)$ \\
$\mathrm{Hb}$ & $15.2 \mathrm{~g} / \mathrm{dL}(13.2-17.3)$ \\
$\mathrm{RBC}$ & $473 \times 10^{4} / \mu \mathrm{L}(402-570)$ \\
\hline $\mathrm{WBC}$ & $6,900 / \mu \mathrm{L}(4,000-9,600)$ \\
\hline Neutro & $48.8 \%(42.2-73.2)$ \\
\hline Lymph & $23.4 \%(20.1-47.3)$ \\
\hline Eosino & $21.1 \%(0.5-7.3)$ \\
\hline Plt & $23.4 \times 10^{4} / \mu \mathrm{L}(16-35)$ \\
\hline
\end{tabular}

Urinalysis

Protein

Ketone body

$-$

Sugar

Occult blood

Blood chemistry

\begin{tabular}{|c|c|}
\hline $\mathrm{TP}$ & $6.9 \mathrm{~g} / \mathrm{dL}(6.3-7.9)$ \\
\hline Alb & 3.7 g/dL (3.9-5.0) \\
\hline T-Bil & $1.1 \mathrm{mg} / \mathrm{dL}(0.3-1.2)$ \\
\hline D-Bil & $0.4 \mathrm{mg} / \mathrm{dL}(0.0-0.2)$ \\
\hline AST & $28 \mathrm{IU} / \mathrm{L}(13-33)$ \\
\hline ALT & 17 IU/L (8-42) \\
\hline $\mathrm{LDH}$ & 182 IU/L (119-229) \\
\hline ALP & 239 IU/L (115-359) \\
\hline$\gamma \mathrm{GTP}$ & $19 \mathrm{IU} / \mathrm{L}(10-47)$ \\
\hline CK & 100 IU/L (62-287) \\
\hline BUN & $22 \mathrm{mg} / \mathrm{dL}(8-20)$ \\
\hline $\mathrm{Cr}$ & $1.08 \mathrm{mg} / \mathrm{dL}(0.8-1.3)$ \\
\hline eGFR & $53.6 \mathrm{~mL} / \mathrm{min} / \mathrm{m}^{2}$ \\
\hline $\mathrm{Na}$ & $127 \mathrm{mEq} / \mathrm{L}(137-145)$ \\
\hline K & $3.9 \mathrm{mEq} / \mathrm{L}(3.5-4.8)$ \\
\hline $\mathrm{Cl}$ & $87 \mathrm{mEq} / \mathrm{L}(100-107)$ \\
\hline $\mathrm{Ca}$ & $10.2 \mathrm{mg} / \mathrm{dL}(8.9-10.5)$ \\
\hline BG & 88 mg/dL (80-110) \\
\hline T-Chol & $64 \mathrm{mg} / \mathrm{dL}(128-219)$ \\
\hline TG & 58 mg/dL (30-149) \\
\hline CRP & $4.17 \mathrm{mg} / \mathrm{dL}(<0.1)$ \\
\hline Posm & $272 \mathrm{mOsm} / \mathrm{L}(275-290)$ \\
\hline Uosm & $464 \mathrm{mOsm} / \mathrm{L}(50-1,300)$ \\
\hline
\end{tabular}

Hct, hematocrit; $\mathrm{Hb}$, hemoglobin; RBC, red blood cell; WBC, white blood cell; Neutro, neutrophil; Lymph, lymphocyte; eosino, eosinophil; Plt, platelet; TP, total protein; Alb, albumin; T-Bil, total bilirubin; D-Bil, direct bilirubin; AST, aspartate aminotransferase; ALT, alanine aminotransferase; LDH, lactate dehydrogenase; ALP, alkaline phosphatase; $\gamma$ GTP, $\gamma$-glutamyl transpeptidase; CK, creatine kinase; BUN, blood urea nitrogen; $\mathrm{Cr}$, creatinine; eGFR, estimated glomerular filtration rate; BG, blood glucose; T-Chol, total cholesterol; TG, triglyceride; CRP, C-reactive protein; Posm, plasma osmolarity; Uosm, urine osmolarity. Normal ranges are shown in parentheses. 
Table 2 Endocrinological and immunological findings on admission

\begin{tabular}{|c|c|c|c|}
\hline \multicolumn{2}{|c|}{ Endocrinological examination } & \multicolumn{2}{|l|}{ Immunological examination } \\
\hline ACTH & $4.9 \mathrm{pg} / \mathrm{mL}(7.2-63.3)$ & \multirow{3}{*}{$\begin{array}{l}\operatorname{IgG} \\
\text { IgG4 }\end{array}$} & \multirow[t]{2}{*}{$921 \mathrm{mg} / \mathrm{dL}(870-1,700)$} \\
\hline Cortisol & $1.7 \mu \mathrm{g} / \mathrm{dL}(2.3-19.4)$ & & \\
\hline DHEAS & 207 ng/mL $(240-2,440)$ & & \multirow{3}{*}{$\begin{array}{c}60 \text { mg/dL (4-108) } \\
268 \text { mg/dL (110-410) }\end{array}$} \\
\hline $\mathrm{GH}$ & $0.09 \mathrm{ng} / \mathrm{mL}(<2.1)$ & \multirow{2}{*}{$\operatorname{IgA}$} & \\
\hline IGF-1 & $31 \mathrm{ng} / \mathrm{mL}(70-219)$ & & \\
\hline PRL & $19.8 \mathrm{ng} / \mathrm{mL}(3.58-12.78)$ & $\operatorname{IgM}$ & 29 mg/dL (35-220) \\
\hline TSH & $2.48 \mu \mathrm{U} / \mathrm{mL}(0.35-4.94)$ & \multirow[t]{2}{*}{$\mathrm{CH} 50$} & \multirow{2}{*}{$45.2 \mathrm{ng} / \mathrm{mL}(30-46)$} \\
\hline FT4 & $1.17 \mathrm{ng} / \mathrm{dL}(0.7-1.48)$ & & \\
\hline FT3 & $2.81 \mathrm{pg} / \mathrm{mL}(1.71-3.71)$ & ANA & negative \\
\hline TGHA & $<100 \times$ & \multirow[t]{2}{*}{ sIL-2R } & \multirow[t]{2}{*}{364 U/mL (135-483) } \\
\hline MCHA & $<100 \times$ & & \\
\hline Thyroglobulin & $8.79 \mathrm{ng} / \mathrm{mL}(0-32.6)$ & $\mathrm{ACE}$ & $10.2 \mathrm{IU} / \mathrm{L}(8.3-21.4)$ \\
\hline LH & $8.4 \mathrm{mIU} / \mathrm{mL}(0.79-5.72)$ & \multirow[t]{3}{*}{ Anti-pituitary cell antibody-1 } & \multirow[t]{3}{*}{ negative } \\
\hline FSH & $3.0 \mathrm{mIU} / \mathrm{mL}(2.3-22.1)$ & & \\
\hline Testosterone & $2.81 \mathrm{ng} / \mathrm{mL}(1.31-8.71)$ & & \\
\hline
\end{tabular}

DHEAS, dehydroepiandrosterone sulfate; IGF-1, insulin-like growth factor-1; PRL, prolactin; TGHA, thyroid test; MCHA, microsome test; Ig, immunoglobulin; CH50, complement activities; ANA, anti-nuclear antibody; sIL-2R, soluble interleukin 2 receptor; ACE, angiotensin-converting enzyme. Normal ranges are shown in parentheses.
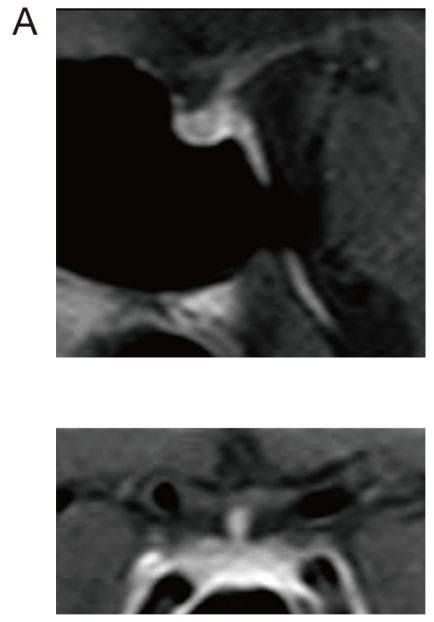

B
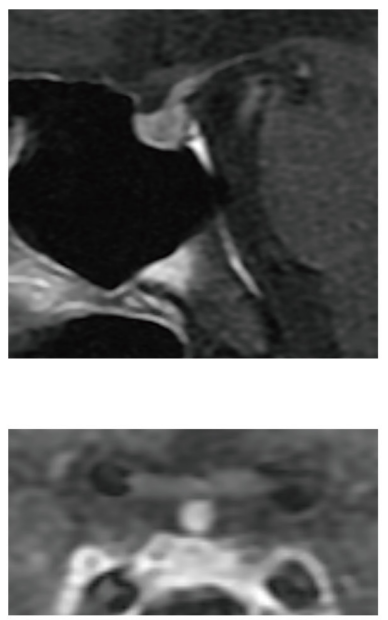

C
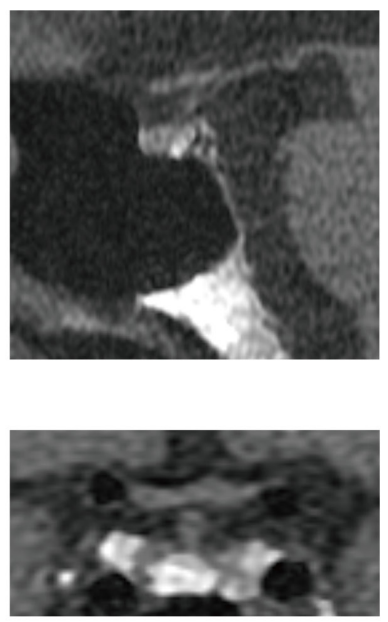

Fig. 2 Sagittal and coronal sections of the pituitary gland on magnetic resonance imaging (MRI) scans

Compared with the findings on a MRI scan performed on July 2015 (A), mild enlargement of the pituitary gland and thickening of the stalk with homogenous enhancement were observed in T1-weighted images on a MRI scan performed on d5 (B). The enlargement of the pituitary gland and thickening of the stalk improved in T1-weighed images on a plain MRI scan performed two months after the $7^{\text {th }}$ administration of nivolumab (C).

itor-induced hypophysitis was previously suggested to be caused by immune-mediated mechanisms [8, 10-12], we measured serum levels of anti-pituitary cell antibody-1, which recognizes the rat pituitary gland (Bio Medical Laboratories, Inc., Japan). However, the anti-pituitary cell antibody-1 was negative. Antithyroid antibodies, which have been reported to be positive and highly prevalent in idiopathic isolated
ACTH-deficient patients, were also negative $[14,15]$. Although invasive pituitary biopsy was not performed on the advanced cancer patient from an ethical view point, we clinically excluded other potential causes of the pituitary/stalk enlargement such as IgG4-related diseases, sarcoidosis, or malignant lymphoma by measuring immunological markers specific for the individual diseases (Table 2). 
A detailed assessment of anterior pituitary functions with hypothalamic hormone challenges was performed on $\mathrm{d} 7$ and $\mathrm{d} 8$ (Fig. 3). The results obtained showed a disturbance in the secretion of ACTH in the $\mathrm{CRH}$ or growth hormone-releasing peptide-2 (GHRP-2) tests and a delayed response by TSH in the TRH test (a peak response was observed at $60 \mathrm{~min}$ ). Prolactin secretion was normal in the TRH test, and the secretion of GH and LH/FSH was also normal in the GHRP-2 and LH-RH tests, respectively. After the administration of hydrocortisone, the patient developed severe thirst, polydipsia, and polyuria $(\sim 4,000 \mathrm{~mL} / \mathrm{d})$. However, the $5 \%$ hypertonic saline tolerance test revealed an appropriate increase in urine osmolality and serum antidiuretic hormone (ADH) levels (data not shown), excluding central diabetes insipidus. With a replacement dose of hydrocortisone, nivolumab was administered three weeks later with close monitoring. Polydipsia and polyuria improved and the patient was discharged. The general condition of the patient did not deteriorate and basal pituitary hormone levels were stable (Table 3). An MRI scan performed two months after the $7^{\text {th }}$ administration of nivolumab revealed improvements in the enlargement of the pituitary gland and thickening of the stalk (Fig. 2C).

\section{Discussion}

Ipilimumab, an anti-CTLA-4 mab, has been shown to induce pituitary dysfunction at varying incidences of $0-17 \%$, and at $4.5 \%$ in the largest trial $[10,16]$. The latest review summarizing large cohorts of ipilimumab-treated malignant melanoma patients suggested that the incidence of ipilimumab-induced hypophysitis was approximately $10-15 \%$ [12]. This increased incidence may be partly attributed to improvements in the clinical recognition of ipilimumab-induced hypophysitis [12]. The onset of pituitary damage secondary to an anti-CTLA-4 mab is independent of tumor types [8], and a male gender and older age have been identified as risk factors for ipilimumab-induced hypophysitis [11]. Only two patients receiving ipilimumab have been reported to develop diabetes insipidus [12]. The degree of the pituitary enlargement in ipilimumabinduced hypophysitis was previously demonstrated to be mild and no patient exhibited optic chiasm compression due to an enlarged pituitary gland $[8,11,12]$. These clinical characteristics of ipilimumab-induced hypophysitis differ from those of idiopathic $\mathrm{AH}$, which

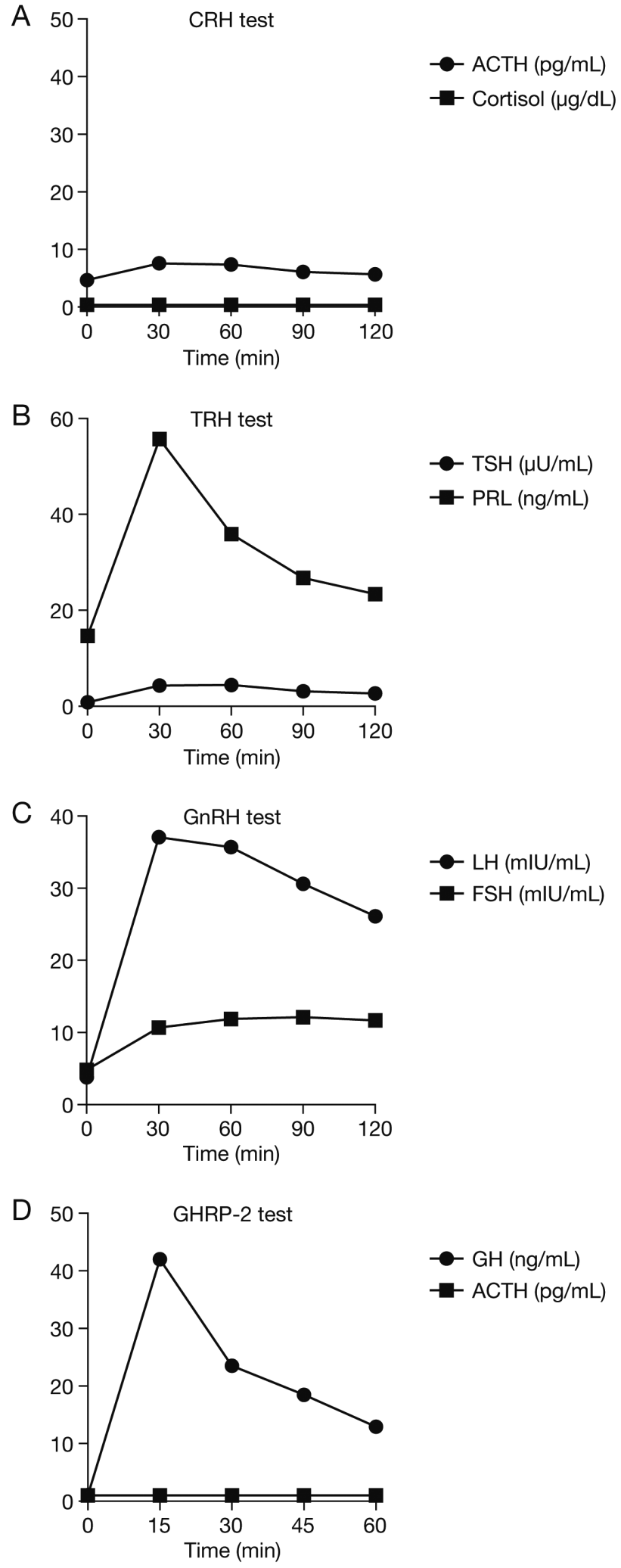

Fig. 3 Results of CRH (A), TRH (B), GnRH (C) and growth hormone-releasing peptide-2 (GHRP-2) (D) tests performed on $\mathrm{d} 7$ and $\mathrm{d} 8$ after admission. 
Table 3 Hematological, biochemical, and endocrinological findings two months after the 7 th administration of nivolumab

\begin{tabular}{|c|c|}
\hline \multicolumn{2}{|c|}{ Cell blood count } \\
\hline Hct & $37.3 \%(40.0-52.0)$ \\
\hline $\mathrm{Hb}$ & $12.3 \mathrm{~g} / \mathrm{dL}(13.2-17.3)$ \\
\hline $\mathrm{RBC}$ & $375 \times 10^{4} / \mu \mathrm{L}(402-570)$ \\
\hline WBC & $7,300 / \mu \mathrm{L}(4,000-9,600)$ \\
\hline Neutro & $59.7 \%(42.2-73.2)$ \\
\hline Lymph & $26.1 \%(20.1-47.3)$ \\
\hline Eosino & $0.32 \%(0.5-7.3)$ \\
\hline Plt & $22.7 \times 10^{4} / \mu \mathrm{L}(16-35)$ \\
\hline \multicolumn{2}{|c|}{ Blood chemistry } \\
\hline $\mathrm{TP}$ & $6.2 \mathrm{~g} / \mathrm{dL}(6.3-7.9)$ \\
\hline Alb & $3.6 \mathrm{~g} / \mathrm{dL}(3.9-5.0)$ \\
\hline T-bil & $0.6 \mathrm{mg} / \mathrm{dL}(0.3-1.2)$ \\
\hline AST & $23 \mathrm{U} / \mathrm{L}(13-33)$ \\
\hline ALT & $22 \mathrm{U} / \mathrm{L}(8-42)$ \\
\hline $\mathrm{LDH}$ & 272 U/L (119-229) \\
\hline ALP & $156 \mathrm{U} / \mathrm{L}(115-359)$ \\
\hline$\gamma \mathrm{GTP}$ & $20 \mathrm{U} / \mathrm{L}(10-47)$ \\
\hline BUN & $15 \mathrm{mg} / \mathrm{dL}(8-20)$ \\
\hline $\mathrm{Cr}$ & $0.87 \mathrm{mg} / \mathrm{dL}(0.65-1.07)$ \\
\hline $\mathrm{Na}$ & $145 \mathrm{mEq} / \mathrm{L}(137-145)$ \\
\hline $\mathrm{K}$ & $3.9 \mathrm{mEq} / \mathrm{L}(3.5-4.8)$ \\
\hline $\mathrm{Cl}$ & $106 \mathrm{mEq} / \mathrm{L}(100-107)$ \\
\hline
\end{tabular}

Endocrinological examination

\begin{tabular}{lc} 
ACTH & $1.2 \mathrm{pg} / \mathrm{mL}(7.2-63.3)$ \\
Cortisol & $16.3 \mu \mathrm{g} / \mathrm{dL}(2.3-19.4)$ \\
\hline GH & $0.15 \mathrm{ng} / \mathrm{mL}(<2.1)$ \\
\hline PRL & $7.3 \mathrm{ng} / \mathrm{mL}(3.58-12.78)$ \\
\hline TSH & $0.52 \mu \mathrm{U} / \mathrm{mL}(0.35-4.94)$ \\
\hline FT4 & $0.79 \mathrm{ng} / \mathrm{dL}(0.7-1.48)$ \\
\hline FT3 & $2.42 \mathrm{pg} / \mathrm{mL}(1.71-3.71)$ \\
\hline LH & $3.6 \mathrm{mIU} / \mathrm{mL}(0.79-5.72)$ \\
FSH & $5.3 \mathrm{mIU} / \mathrm{mL}(2.3-22.1)$ \\
\hline Testosterone & $5.61 \mathrm{ng} / \mathrm{mL}(1.31-8.71)$ \\
\hline
\end{tabular}

Hct, hematocrit; Hb, hemoglobin; RBC, red blood cell; WBC, white blood cell; Neutro, neutrophil; Lymph, lymphocyte; eosino, eosinophil; Plt, platelet; TP, total protein; Alb, albumin; T-Bil, total bilirubin; D-Bil, direct bilirubin; AST, aspartate aminotransferase; ALT, alanine aminotransferase; LDH, lactate dehydrogenase; ALP, alkaline phosphatase; $\gamma$ GTP, $\gamma$-glutamyl transpeptidase; BUN, blood urea nitrogen; Cr, creatinine. Normal ranges are shown in parentheses. has a higher incidence among younger females and sometimes cause diabetes insipidus and visual disturbances due to the compression of the optic chiasm by the enlarged pituitary gland and stalk [1].

Idiopathic isolated ACTH deficiency may be caused by $\mathrm{AH}$, as evidenced by the pathological demonstration of lymphocyte infiltration in the anterior pituitary gland, an association with autoimmune diseases in other organs such as Hashimoto's thyroiditis, vitiligo, and premature ovarian failure, and the presence of anti-pituitary antibodies $[1,14,15]$. In hypophysitis induced by immune-checkpoint inhibitors, enhanced immune responses have also been suggested to play pathological roles [8, 10-12]. However, no biopsyproven ipilimumab- or nivolumab-induced $\mathrm{AH}$ has been reported [12]. In addition, the prevalence of anti-pituitary antibodies remains unknown in large cohorts of patients with immune-checkpoint inhibitorinduced hypophysitis, although endocrine irAEs such as destructive thyroiditis and fulminant type I diabetes mellitus have been reported in patients treated with immune-checkpoint blocking agents [9, 17]. Ricciuti A et al. recently reported that the human pituitary gland was the best substrate to detect anti-pituitary antibodies by indirect immunofluorescence [18]. Since we measured anti-pituitary antibodies using rat pituitary sections, further studies using human pituitary sections may be useful for detecting anti-pituitary antibodies in the present case.

In contrast to its stronger relationship with hypophysitis in melanoma patients treated with ipilimumab, the incidence of nivolumab-induced hypophysitis is markedly lower $(<1 \%)$ in Western countries [12]. These marked differences in incidences between ipilimumab- and nivolumab-induced hypophysitis may be attributed to functional differences in the processes of $\mathrm{T}$ cell activation [5] and the ectopic expression of CTLA-4 in the human pituitary gland that may be targeted by an anti-CTLA-4 mab [19]. In a previously performed literature search, the number of reported idiopathic AH cases was the largest in Japan (130 of 379 cases, $34 \%$ ) among the 27 countries examined [1]. A recent review further pointed out that approximately $30 \%$ of more than 750 case reports of primary hypophysitis were from Japan [20]. These findings indicate that geographical and/or ethnic variations exist in the risk of developing primary $\mathrm{AH}$; however, this high prevalence may simply be attributed to the more frequent diagnosis of hypophysitis in Japan than in other 
countries. However, it currently remains unknown whether the incidence and clinical manifestations of immune-checkpoint inhibitor-induced hypophysitis in large Japanese cohorts are similar to those observed in Western countries.

A prospective randomized study has not yet been conducted to evaluate the long-term efficacy and safety of high-dose glucocorticoid therapy in patients with immune-checkpoint inhibitor-induced hypophysitis or in those with idiopathic AH [21]; however, its effectiveness to ameliorate enlargements in the pituitary gland in the acute phase has been empirically appreciated $[8,11,12,21]$. In many case series, high-dose glucocorticoid therapy (for example, prednisolone $1 \mathrm{mg} / \mathrm{kg}$ body weight) has been prescribed for most cases of ipilimumab-induced hypophysitis $[8,11,12]$. However, although there have been concerns that highdose glucocorticoid therapy may affect the anti-tumor efficacy of ipilimumab, previous findings suggest that the function of activated T cells is not inhibited by glucocorticoids $[22,23]$. Despite the administration of high-dose glucocorticoid therapy, hormonal deficiencies persisted in most cases $[8,11,12]$. Large-dose glucocorticoid therapy may affect the quality of life (QOL) of advanced cancer patients by extending hospitalization and adverse events such as steroid-induced diabetes mellitus, peptic ulcers, infections, glaucoma, and accelerated osteoporosis, as reported previously in idiopathic AH patients [21]. Based on these clinical experiences of the treatment of primary $\mathrm{AH}$ and druginduced hypophysitis, we administered hydrocortisone $(100 \mathrm{mg} / \mathrm{d})$ i.v. for two days in order to achieve rapid improvements in the patient's general condition and then switched to a replacement dose of oral hydrocortisone $(30 \mathrm{mg} / \mathrm{d}$ for 1 week and subsequently tapered to $20 \mathrm{mg} / \mathrm{d}$ ). With the replacement dose of hydrocortisone, the $7^{\text {th }}$ administration of nivolumab was successfully performed without deteriorations in the hormonal profile in our case (Table 3). Similar to the present case, the successful management of ipilimumabinduced hypophysitis with hydrocortisone replacement therapy has been reported [24]. A strategy for the treatment of idiopathic $\mathrm{AH}$ has recently been proposed that also emphasizes a conservative treatment [21]. As recommended by others in the absence of comparative data to demonstrate the advantages of higher doses of glucocorticoids [11, 12], high-dose glucocorticoid therapy may be reserved for patients with significant hyponatremia, severe headaches, or a marked pituitary enlargement that abuts or approaches the optic chiasm. Immune-checkpoint inhibitors induce not only endocrine irAEs, but also various irAEs in other organs such as dermatitis with rashes, colitis, hepatitis, pneumonitis, sarcoidosis, pancreatitis, fulminant type I diabetes mellitus, iridocyclitis, lymphadenopathy, nephritis, and neuropathies $[8,11,12,17]$. When patients treated with immune-checkpoint inhibitors develop hypophysitis simultaneously with life-threatening irAEs in other organs such as pneumonitis, a treatment with large doses of glucocorticoids may need to be prioritized.

In summary, we encountered nivolumab-induced hypophysitis associated with secondary adrenal insufficiency in an advanced malignant melanoma patient. Ishikawa et al. recently reported a case of nivolumabinduced hypophysitis in a malignant melanoma patient with a normal pituitary gland and stalk [25]. To the best of our knowledge, the present report is the first presentation of detailed clinical and hormonal information associated with nivolumab-induced hypophysitis showing an enlarged pituitary gland and thickened stalk in Japan. Since the enlargement/thickening of the pituitary gland/stalk are important MRI findings for the diagnosis of $\mathrm{AH}$ and have previously been reported to be very mild in ipilimumab-induced hypophysitis $[8,11,12]$, a careful evaluation of the pituitary/stalk size in a patient with hypophysitis will be necessary through a comparison with MRI findings obtained before the administration of immune-checkpoint inhibitors or after glucocorticoid treatments. Since the indications for these emerging immune-checkpoint inhibitors will be widened to other advanced cancers in Japan, oncologists and endocrinologists need to be familiar with endocrine irAEs such as potentially lifethreatening hypophysitis. The scheduled monitoring of ACTH, cortisol, TSH, and free T4 levels as well as an awareness and suspicion of hypophysitis based on patient symptoms such as headache, fatigue, nausea, and appetite loss will lead to a more timely diagnosis and appropriate treatment that will ultimately retain QOL in advanced malignancy patients and minimize the interval of treatments with immune-checkpointblocking agents for hypophysitis.

\section{Disclosure}

None of the authors have any potential conflicts of interest associated with this manuscript. 


\section{References}

1. Caturegli P, Newschaffer C, Olivi A, Pomper MG, Burger PC, et al. (2005) Autoimmune hypophysitis. Endocr Rev 26: 599-614.

2. Umehara H, Okazaki K, Masaki Y, Kawano M, Yamamoto M, et al. (2012) A novel clinical entity, IgG4-related disease (IgG4RD): general concept and details. Mod Rheumatol 22: 1-14.

3. Bando H, Iguchi G, Fukuoka H, Taniguchi M, Yamamoto M, et al. (2013) The prevalence of IgG4related hypophysitis in 170 consecutive patients with hypopituitarism and/or central diabetes insipidus and review of the literature. Eur J Endocrinol 170: 161-172.

4. Imura H, Nakao K, Shimatsu A, Ogawa Y, Sando T, et al. (1993) Lymphocytic infundibuloneurophysitis as a cause of central diabetes insipidus. $N$ Engl J Med 329: 683-689.

5. Nishimura H, Honjo T (2001) PD-1: an inhibitory immunoreceptor involved in peripheral tolerance. Trends Immunol 22: 265-268.

6. Sharma P, Wagner K, WolchoK JD, Allison JP (2011) Novel cancer immunotherapy agents with survival benefit: recent successes and next steps. Nat Rev Cancer 11: 805-812.

7. Topalian SL, Hodi FS, Brahmer JR, Gettinger SN, Smith DC, et al. (2012) Safety, activity, and immune correlates of anti-PD-1 antibody in cancers. $N$ Engl $J$ Med 366: 2443-2454.

8. Torino F, Barnabei A, Paragliola RM, Marchetti P, Salvatori R, et al. (2013) mAbs and pituitary dysfunction: clinical evidence and pathogenic hypotheses. Eur J Endocrinol 169: R153-R164.

9. Torino F, Barnabei A, Paragliola R, Baldelli R, Appetecchia M, et al. (2013) Thyroid dysfunction as an unintended side effect of anticancer drugs. Thyroid 23: 1345-1366.

10. Corsello SM, Barnabei A, Marchetti P, Vecchis LD, Salvatori R, et al. (2013) Endocrine side effect induced by immune checkpoint inhibitors. J Clin Endocrinol Metab 98: 1361-1375.

11. Faje AT, Sullivan R, Lawrence D, Tritos NA, Fadden $\mathrm{R}$, et al. (2014) Ipilimumab-induced hypophysitis: A detailed longitudinal analysis in a large cohort of patients with metastatic melanoma. J Clin Endocrinol Metab 99: 4078-4085.

12. Faje A (2016) Immunotherapy and hypophysitis. Pituitary 19: 82-92.

13. https://www.opdivo.jp/contents/clinical_trial/
14. Kasperlik-Załuska AA, Czarnocka B, Czech W (2003) Autoimmunity as the most frequent cause of idiopathic secondary adrenal insufficiency: report of 111 cases. Autoimmunity 36: 155-159.

15. Caturegli P, Lupi I, Landek-Salgado M, Kimura H, Rose NR (2008) Pituitary autoimmunity: 30 years later. Autoimmun Rev 7: 631-637.

16. Hodi FS, O'Day SJ, McDermott DF, Weber RW, Sosman JA, et al. (2010) Improved survival with ipilimumab in patients with metastatic melanoma. $N$ Engl $J$ Med 363: 711-723.

17. Teply BA, Lipson EJ (2014) Identification of management of toxicities from immune checkpoint-blocking drugs. Oncology (Williston Park) 28 Suppl 3: 30-38.

18. Ricciuti A, De Remigis A, Landek-Salgado MA, De Vincentiis L, Guaraldi F, et al. (2014) Detection of pituitary antibodies by immunofluorescence: Approach and results in patients with pituitary diseases. $J$ Clin Endocrinol Metab 99: 1758-1766.

19. Iwama S, De Remigis A, Callahan MK, Slovin SF, Wolchok JD, et al. (2014) Pituitary expression of CTLA-4 mediates hypophysitis secondary to administration of CTLA-4 blocking antibody. Sci Transl Med 6: $230 \mathrm{ra} 45$.

20. Caturegli P, Iwama S (2013) From Japan with Love: Another tessera in the hypophysitis mosaic. J Clin Endocrinol Metab 98: 1865-1868.

21. Honegger J, Buchfelder M, Schlaffer S, Droste M, Werner S, et al. (2015) Treatment of primary hypophysitis in Germany. J Clin Endocrinol Metab 100: 3460-3469.

22. Downey SG, Klapper JA, Smith FO, Yang JC, Sherry RM, et al. (2007) Prognostic factors related to clinical response in patients with metastatic melanoma treated by CTL-associated antigen-4 blockade. Clin Cancer Res 13: 6681-6688.

23. Hinrichs, Palmer DC, Rosenberg SA, Restifo NP (2005) Glucocorticoids do not inhibit antitumor activity of activated CD8+ T cells. J Immunother 28: 517-524.

24. Marlier J, Cocquyt V, Brochez L, Van Bella S, Kruse V (2014) Ipilimumab, not just another anti-cancer therapy: hypophysitis as side effect illustrated by four casereports. Endocrine 47: 878-883.

25. Ishikawa M, Oashi K (2016) Case of hypophysitis caused by nivolumab. J Dermatol DOI 10.1111/13468138.13437. 